\title{
Joining the conspiracy? Negotiating ethics and emotions in researching (around) AIDS in southern Africa
}

\author{
Nicola Ansell and Lorraine van Blerk ${ }^{1}$ \\ Department of Geography and Earth Sciences \\ Brunel University, Uxbridge, UB8 3PH \\ nicola.ansell@brunel.ac.uk; lorraine.van.blerk@brunel.ac.uk
}

\begin{abstract}
AIDS is an emotive subject, particularly in southern Africa. Among those who have been directly affected by the disease, or who perceive themselves to be personally at risk, talking about AIDS inevitably arouses strong emotions - amongst them fear, distress, loss and anger. Conventionally, human geography research has avoided engagement with such emotions. Although the ideal of the detached observer has been roundly critiqued, the emphasis in methodological literature on 'doing no harm' has led even qualitative researchers to avoid difficult emotional encounters. Nonetheless, research is inevitably shaped by emotions, not least those of the researchers themselves. In this paper, we examine the role of emotions in the research process through our experiences of researching the lives of 'Young AIDS migrants' in Malawi and Lesotho. We explore how the context of the research gave rise to the production of particular emotions, and how, in response, we shaped the research, presenting a research agenda focused more on migration than AIDS. This example reveals a tension between universalised ethics expressed through ethical research guidelines that demand informed consent, and ethics of care, sensitive to emotional context. It also demonstrates how dualistic distinctions between reason and emotion, justice and care, global and local are unhelpful in interpreting the ethics of research practice.
\end{abstract}

Key words: emotion; ethics; ethical codes; HIVIAIDS; Africa

\section{Introduction}

The past two decades have witnessed a plethora of articles discussing the ethics of conducting human geographical research. The roots of this concern can be traced to humanistic geography and the rejection of the ideal of objectivity by many geographers. Recently, however, Widdowfield (2000) has pointed to the fact that

\footnotetext{
${ }^{1}$ Nee Young.
} 
despite recognition of subjectivity and efforts to engage reflexively with research, almost all accounts of the research process omit discussion of the influence of emotions on that process.

The fact that emotions are excluded from reports of research does not mean that they are not taken account of in the design and management of research. We would suggest, however, that the primary emphasis has been on minimising the 'interference' of emotions in the research process and in particular the avoidance of situations of heightened emotion within research encounters. This avoidance may in part be attributable to the persistence of a tendency to privilege 'masculine' ways of knowing: 'the Academy appearing to remain wary of acknowledgement and expressions of emotion' (Widdowfield 2000, 200). Avoiding emotional encounters is not, however, simply an endeavour to remain objectively detached. It is also related to nervousness about intervening in people's lives in a negative way: to lay bare a person's emotions is seen as an intrusion into their privacy. Arousing negative emotions in research participants seems counter to injunctions to researchers to 'do no harm.'

Yet the relationship between emotions and ethics in the research process is much more complex than this. The first part of this paper examines contemporary literature on the relationship between ethics and emotions. On the basis of the co-dependency between emotion and cognition, we argue that emotion and reason are not binary opposites, and that this has important implications for ethics. We explore the tensions between an 'ethics of care' grounded in interpersonal emotional relations and an 'ethics of justice' based on universal principles of fairness, deconstructing the mapping of these ethical modalities onto a local-global binary. We argue that taking account of emotions through application of an ethics of care is appropriate to research encounters with people in Third World settings, but may conflict with ethical codes which seek to impose universal ethical principles. The second part of the paper applies these ideas to specific research conducted among AIDS-affected people in southern Africa, which inevitably required us to address difficult issues concerning both emotions and ethics. The (global and local) discourses that surround AIDS in southern Africa may provoke a range of uncomfortable emotions among researchers and research subjects. We outline how we managed the research in order to minimise the distress and discomfort to all involved. Nonetheless, we recognise that some of the strategies we employed, notably underplaying the significance of AIDS to the research, would contravene the injunctions of universal 
ethical codes. Not only did we fail to fully inform our participants of our agenda, but we may also have contributed to the dangerous silencing of the pandemic. Through problematising individual research encounters, we argue that denial might, with certain provisos, be justifiable as part of an ethic of care. We conclude that ethical research needs to take account of the emotions of both researchers and researched, but also to acknowledge that emotions alone do not present us with clear-cut answers.

\section{Emotions and ethics}

Emotions have been neglected, not only by geographers, but throughout the social sciences more generally. This neglect of emotion is usually traced to the Cartesian separation of mind and body that has characterised Western thought from the Enlightenment onwards. The mind/body dualism is paralleled in a distinction between reason and emotion, reason being associated with the mind and emotion with the body. Mind and reason are accorded a higher status such that '[i]n the end, not only was emotion not rational, even studying it was probably not rational' (Damasio 1999, p. 39).

The distinction between reason and emotion was particularly promoted by Immanuel Kant and extended to the realm of ethics. In Kantian terms, ethics is governed by universal principles which are established through the application of reason. Emotions are seen as irrelevant: 'the exclusion of emotions from ethics was based on their supposed irrationality (or nonrationality), their physiological, bodily, and 'bestial' nature, their capriciousness, their apparent involuntariness' (Solomon 1996, p. 533).

These views have been progressively challenged from a number of quarters. Nietzche, for instance, believed life should be governed not by reason but by uninhibited emotions (Solomon 1996). Eighteenth century Scottish philosopher, David Hume declared that 'reason is, and ought to be, the slave of the passions' (cited in Solomon 1996, p. 531). Hume developed a 'moral sentiment theory' wherein morals were based on a set of emotions he termed 'sympathy' (Solomon 1996). More recent critics, however, have questioned the fundamental dualisms underlying the exclusion of emotion from understandings of the ethical domain.

First, some have questioned the extent to which emotion originates in the body and not the mind. Solomon (1997), for instance, disputes the dominant view that emotions are physiological and essentially irrational aspects of our animal nature. 
Instead, he understands emotions as ideational - a form of cognition rather than simply physiological responses.

Second, research has demonstrated the role of emotion in rational thinking. On the basis of experiments undertaken with brain-damaged people, Damasio (1999, p. 41) concludes: '[i]t certainly does not seem true that reason stands to gain from operating without the leverage of emotion. On the contrary, emotion probably assists reasoning, especially when it comes to personal and social matters involving risk and conflict.' The centrality of emotions to rationality is increasingly argued, particularly in relation to the roles of preferences, values and judgement in decision-making (Benner 2000; Wenstop and Magnus 2001). '[T]he ideas that constitute emotions are, at least in part, evaluative judgements' (Solomon 1997, p. 292). Damasio (1994) suggests that even the most primitive perception entails evaluation. As a consequence, a growing role is seen for the emotions in ethical thought and action. If emotions are judgements, then they are inevitably implicated in ethics (Solomon 1996). For Damasio (1999, p. 55), '[e]motions are inseparable from the idea of reward or punishment, of pleasure or pain, of approach or withdrawal, of personal advantage and disadvantage. Inevitably, emotions are inseparable from the idea of good and evil.' However, while emotions may be fundamental to consciousness, existing prior to conscious reasoning, they cannot be a substitute for reason (Damasio 1999). Judgement need not be conscious, reflective or articulate (Solomon 1997). The contribution of emotion to our judgement of right and wrong may be subtler: acting on a perceived moral obligation may, for instance, give the individual a sentiment of approval (Solomon 1996).

So long as emotion is seen as a purely individual phenomenon, however, it can only relate to a narrow and limited conception of ethics. A deeper imbrication of emotion and ethics becomes apparent when emotion is recognised as not only embodied and cognitive, but also in part socially constructed. Here, Solomon and Damasio part company. Damasio (1999) distinguishes six 'primary emotions' (happiness, sadness, fear, anger, surprise and disgust), which he ascribes to the individual, from other 'secondary' or 'social emotions' (e.g. embarrassment, jealousy, guilt, pride), ascribed to the social realm. Solomon, by contrast, while recognising that there are many kinds of emotions and that not all can be understood in the same way (Solomon 1996), argues that 'most of our emotions are social, not only in their context but in their content. They are about other people, even when they seem to be about ourselves' (Solomon 1997, p. 300). Solomon (1997, p. 297) defines emotions as 
'ways of viewing and engaging the world.' They are not 'something inaccessibly 'inner' and 'private' ... but a public and interpersonal phenomenon' (Solomon 1997, p. 293). Although partly biological-physiological, they are 'in part learned and cultivated in society' (Solomon 1997, p. 291). Benner (2000), too, asserts that the 'primary emotions' are always about something or in relation to something, and hence are social, along with background emotions (what might be termed 'feelings', e.g. well-being, malaise, calm or tension) which, while not specifically related to current events, are nonetheless embodied and impinge on relationships with others.

This view of emotions as social is fundamental to the 'ethics of care' popularised by Carol Gilligan (1982). Gilligan, a psychologist working within feminist theory, stresses emotions such as care and trust as the cornerstone of ethics. In an account of the gendering of Western ethics, she states that: '[t]he moral imperative that emerges repeatedly in interviews with women is an injunction to care ... For men, the moral imperative appears rather as an injunction to respect the rights of others and thus to protect from interference the rights to life and self-fulfilment' (Gilligan 1982, p. 100). It is the Kantian-inspired and masculine-coded ethics of rights that have come to dominate Western thinking on ethics. The application of universal principles of fairness and means-ends rationality emphasises individuality and assumes an autonomous moral agent. In contrast, 'concern with relationships appears as a weakness of women rather than as a human strength' (Gilligan 1982, p. 17, after Miller 1976).

For Gilligan, women's moral judgements, characterised by inter-personal emotions of compassion and tolerance, represent an undervalued ethics of care. Gilligan calls for a situational ethics, wherein relationships with others are of paramount importance (Benner 2000), calling into question 'the idea that ethical practice necessarily entails the consistent application of universal principles' (Gormley and Bondi 1999, p. 259).

An ethics of care carries with it a particular conception of moral agency. For Benner (2000, p. 17), '[o]ur moral agency is embodied, and socially embedded, even in our most independent actions.' An overly cognitive notion of action as embodying choice but not emotion or effort is believed to lead to a diminished understanding of agency (Campbell 1999). Furthermore, 'a moral stance in the face of tragedy requires compassion for the commitment to be effective' (Ruiz and Vallejos 1999, p.5). 
'Moral agency, then, can be less mechanistic and less deterministic than Descartes' vision of the subjective mind acting on an object world through clear intentions. Also it can be considerably more responsive and generative than the Kantian vision or the autonomous choice maker directed by pure will and intellect, uninfluenced by emotion and emotional affinities. Both of these visions of the person offer a profound respect for the powers of the individual to choose or act, but they ignore our embodied interdependence that provides the very ground for doing so' (Benner 2000, p.16).

Care ethics have been challenged on the basis that it is difficult to envisage how involuntary emotions can form a basis for ethical action. According to some care ethicists, caring is a natural impulse and not fulfilled as a duty. Indeed, for Benner (2000), caring fuelled by guilt is often accompanied by contempt for and disinterest in the people being helped. Yet if we have no control over our emotions, it would seem that can we have no responsibility either. 'Either you feel sympathy or you don't; and if you don't, how can the 'ethics of care' make any moral demand on you?' (Paley 2002 , p. 140). This critique is, however, based on an understanding of emotions as purely physiological. If emotions are understood as partly cognitive, this allows us greater responsibility for the ways we respond to others. For Solomon (1997, p. 297), emotions 'are not (usually) deliberative, and they are often spontaneous, habitual, unthinking, 'natural' ... they are not full-blooded intentional actions, but, more important, they do not just happen to us either. They are an essential part of our repertoire of responses to the world.' While we may lack full command of our emotional reactions, emotions are part of the way we actively engage with the world, and we are not powerless in that engagement.

The view that emotion can partly serve intention may also be expressed as moral motivation, 'the sentiments which induce people to act in pursuit of a more equal and caring world' (Silk 2000, 306). This is central to many religions. Zizek (2000), for instance, argues that 'agape', the Christian concept of love as charity, should be viewed 'as a self-suppressing duty to love neighbours and care for them, as hard work, as something to be accomplished through the strenuous effort of fighting and inhibiting one's pathological inclinations' (cited in Cloke 2002, p. 594).

The second serious difficulty that many have with the notion of an ethics of care is its seeming failure to address questions of equity and justice (Paley 2002). Our ethical obligation towards 'distant strangers' is rendered problematic, both by rejection of the 
principle of universal fairness, or impartiality, as the primary basis for moral action (Smith 1994), and by the demand that moral action should be rooted in specific caring relationships with others (Smith 1999). Gilligan's original work is often unfairly accused of rejecting universalist principles, although she actually calls for a convergence of ethics of justice with ethics of care: '[w]hile an ethic of justice proceeds from the premise of equality - that everyone should be treated the same an ethic of care rests on the premise of nonviolence - that no one should be hurt. In the representation of maturity, both perspectives converge in the realization that just as inequality adversely affects both parties in an unequal relationship, so too violence is destructive for everyone involved' (Gilligan 1982, p. 174). As Damasio (1999, p. 35) points out, '[h]uman emotion is ... also about the satisfaction of seeing justice served'.

Geographers have debated the merits of a universalist morality compared to a situated or local morality (Corbridge 1998; Cutchin 2002; Proctor 1999). Recognition is growing that a dualistic approach is unhelpful. Smith $(1998$, p. 31) criticises, for instance, '[t]he spatial contention that justice is for the public realm, care for the private.' Whatmore (1997) is equally critical of the simplistic mapping of generalised and concrete others onto a global-local binary. 'The global and the universal are not pre-existing empirical qualities; they are deeply fraught, dangerous, and inescapable inventions' (Haraway 1995, p. xix). While emotions may be situated responses to the world, situations are not simply local. A range of forms of personal (caring) interaction, both mediated and unmediated, take place across physical and cultural distance (Corbridge 1998; Robinson 1999; Silk 1998; Smith 1997).

While ethics of care and ethics of justice do not map directly onto local/global relationships, the application of an ethics of care to people living in distant places and different cultures raises the question of the cultural specificity of emotions. '[l]f emotions are constituted by ideas, and ideas (at least those ideas that constitute emotions) vary from culture to culture, then emotions will vary from culture to culture too' (Solomon 1997, p. 296). Furthermore, there are too few physiological causes and distinct sensations to account for the enormous variety of emotions across the world (Solomon 1997). 'Compassion, or some sort of distanced concern for others, seems to be the presupposition of every society and it is built into virtually every philosophy ... But what 'compassion' means ... is sufficiently different to give us pause, and even fear - not to mention different attitudes of fear and pain - is not obviously 'the same' in all societies' (Solomon 1997, p. 300). If ethics are related to 
emotions but emotions are culturally specific, it becomes more difficult to argue for a universal morality. ${ }^{1}$

\section{The research process: emotions, ethics and codes of practice}

If emotions affect how we, as academics, think and act in relation to other people, they are clearly relevant to the conduct of research. Both researcher and researched have emotions, and these need to be taken into account. '[A]cknowledgeing emotions and emotional exchanges orientates us differently within our research interviews' (Laurier and Parr 2000, 99). While Laurier and Parr question whether it is appropriate to think in terms of managing emotions in an interview, in practice, researchers do take measures to both pre-empt and respond to likely emotional reactions. Furthermore, when we conduct research among 'distant strangers', the interpersonal encounters that we have with them take place within contexts that involve both global and local dimensions. We operate in what Mary Louise Pratt (1992, p. 7) terms a 'contact zone', of 'copresence, interaction, interlocking understandings and practices.' We need, for instance, to take into account the fact that our respondents' emotional responses to given situations may differ from our own and that we may have difficulty understanding them, and they us as a consequence. But we need also to recognise that both we and they respond emotionally to the global inequalities and power relations that are manifest in the research encounter. This is not a simple case of situational versus universal ethics.

The difficulties of justifying ethical research guidelines in practical situations have been acknowledged by geographers (Valentine 2003). 'The imposition of some universal code of professional ethics, even within the confines of a national institution such as the Association of American Geographers or the Royal Geographical Society, faces the opposition of those whose ethics are necessarily contextual' (Smith 1999, p. 283). Nonetheless, many researchers subscribe to codes of research ethics to justify the ethical soundness of their research. One characteristic of these codes, and the focus of this paper, is an insistence on openness about the research. The need for informed consent, in which full details of the purpose of the research are made available to participants, is stressed in most recent guidelines concerning research. The British Sociological Association (2002), for instance, states: 'As far as possible participation in sociological research should be based on the freely given informed consent of those studied. This implies a responsibility on the sociologist to explain in appropriate detail, and in terms meaningful to participants, what the research is about ...' Most guidelines for research with children advocate that 
children are fully involved in all aspects of the research from planning to dissemination. $^{2}$ As Cree et al (2002, p. 48) point out, however, these codes 'offer topics for consideration rather than 'blue-prints' for good practice'. Geographers have argued that they should not be bound by the requirement for informed consent when researching the lives of people who cannot give such consent due to profound intellectual disabilities (Metzel 2000), or where respondents are opposed to the social justice agenda of the researcher (Wilton 2000), provided the respondents are not harmed by the research.

In the case study below, we discuss research in which we were not entirely open to participants about our purpose. The reasons for this relate to the way in which emotions would have entered into the research encounter had we been explicit about our purpose. We argue that we were applying a situated ethics that, rather than abandoning concern for global justice, was prompted by emotional responses to, among other things, the absence of justice, although we cannot say with total confidence that we 'did no harm'.

\section{Case study: Young AIDS migrants research}

In 2001 we conducted research among urban and rural communities in Lesotho and Malawi with the purpose of investigating the experiences of young people who had to move house as a consequence of AIDS among their relatives. These included children whose parents/ guardians had become sick or had died and were no longer able to care for them, and others who moved because their help was needed elsewhere (see Ansell and van Blerk 2004; Young and Ansell 2003). In the course of the research we asked children about the circumstances of their relatives' illnesses/deaths, about how they had felt and the impacts of the death/sickness upon them. When interviewing guardians, we again asked about causes of illness and death, and about the impacts on the children concerned and on other household members. Rates of HIV infection in both Lesotho and Malawi are very high, and about two thirds of orphans in both countries are orphaned by AIDS (USAID/UNICEF/UNAIDS 2002). Nonetheless, although we asked people about sickness and death among their relatives we were less candid in revealing that our research agenda was focused on the impacts of HIVIAIDS. Such an approach is not uncommon: others researching the social impacts of AIDS in Africa also use a proxy such as chronic illness, particularly where, as was the case for us, the cause of illness is seldom closely related to its consequences. 


\section{Contextualising the research encounter: AIDS and its effects}

Across sub-Saharan Africa $7.5 \%$ of $15-49$ year old adults are living with HIV; in Swaziland, Botswana and Lesotho numbers exceed 25\% (UNAIDS 2004). This is only a snapshot picture: an extreme projection suggests that, if current trends continue, as many as $90 \%$ of 15 -year-old boys in Botswana will ultimately die of AIDS (UNAIDS 2000). For the vast majority of individuals, a positive diagnosis means inevitable death within a few years. Few Africans survive more than five years post-diagnosis (Schoepf 2001). AIDS is not merely a death sentence, but also has negative consequences for a person's remaining life, and that of their families. AIDS causes very unpleasant illnesses which are costly to treat. People living with HIVIAIDS (PLWHAs) suffer not only illness, but increasing poverty, associated with costs of treatment and inability to work. Where a productive person becomes sick, their income or value of their labour is lost to their family, as is that of those whose time must be devoted to caring for them. AIDS-affected households commonly become impoverished. Furthermore, the children of those who become sick or die of AIDS may be left with no property and inadequate arrangements for their care. A diagnosis (or even suspicion) of AIDS brings fear and despair, not only for the individual directly affected but also their family.

Emotions are produced in social contexts that are interpreted (in part through emotion) in relation to both universalised ethics of justice and more localised moralities. The nature of the AIDS pandemic in southern Africa is such that research encounters with AIDS-affected people need to take into account the emotions that arise from both the immediate personal situations of the participants but also wider contexts of injustice. While writing on emotion and ethics has focused on the positive emotions that ground ethics of care, research with AIDS-affected people has also to address more negative feelings of anger, guilt, shame and discomfort. Four interrelated framing contexts are considered below, each of which is shown to have shaped the intersubjective production and expression of emotion within the Young AIDS migrants research.

\section{Global inequalities}

That AIDS is wreaking disaster on African individuals and families, when Africa is already so impoverished, is likely to confront most observers as unjust: a sense of injustice that is both rationalised and emotionally felt. While global AIDS discourse focuses on individual risk behaviour, risk, in reality, stems not so much from ignorance of AIDS as from the precarious situations in which millions of people live 
(Farmer et al 2001). Such situations have worsened in recent decades as a consequence of international economic regimes (Schoepf 2001). Both globally and locally, 'the disease is distributed unequally across populations in line with preexisting socio-economic inequalities that could be considered immoral and unjust' (Ashforth 2001, p. 8). The differential availability of care and treatment resources in different parts of the world appears even more unjust when seen in the context of a universal ethics (Baylies and Bujra 1997). Over the past few years the global differences in prognosis for those infected with HIV have become much sharper. New treatments, known collectively as 'Highly Active Antiretroviral Therapies' (HAART), 'have the capacity to transform AIDS from an automatic death sentence to something closer akin to a chronic illness' (Baylies and Bujra 1997, p. 385). Yet these treatments, which now cost about $\$ 200$ per person per year, and would not only save lives, but also benefit families and societies more widely, are unavailable to the vast majority of PLWHAs across sub-Saharan Africa, even while the US government budgets about $\$ 45$ million a year to supply its troops with Viagra (Silverstein 1999).

This global injustice frames the production and expression of emotion in any research encounter with AIDS-affected people in sub-Saharan Africa. Knowledge that the opportunity for life available to people in many Western countries is unavailable to PLWHAs in Africa adds to the sense of guilt that is so often a feature of research in Third World societies. This knowledge, or at least awareness of their own poverty and our relative wealth, also colours the reactions of research respondents. Farmer (1994) drew attention to the way Haitian people associate AIDS with wider political-economic processes, including North American imperialism. Many people we encountered in the course of our research asked for material help. However much we believe our research to be of value to wider southern African society, the fact that our research budget did not provide for us to meet the expectations of the individuals we met generated a sense of impotence (as is often the case when conducting research across such material inequality).

In conducting research concerning AIDS we encountered not only people who were upset and sorrowful, but also, occasionally, people who were angry. In Thibella, a particularly poor neighbourhood of Maseru, people became quite hostile towards us, because we promised no material support - possibly because our visit coincided with that of an NGO AIDS project which was well resourced. Here we felt that research participants deliberately played on our emotions - people would tell tragic stories in the hope of receiving assistance; one woman's tears, which began before the 
research was even introduced to her, appeared to be designed to evoke our sympathy and guilt. In practice, the emotions aroused were more complex annoyance that people were so demanding, manipulative and unwilling to cooperate, but also guilt at feeling annoyed when people clearly are in need. The emotional reactions of both researchers and researched to global inequalities that exacerbate the damage caused by AIDS thus inhibit free dialogue on the subject.

\section{Racialised discourse}

Our research relations with AIDS-affected southern Africans are structured not only by global economic inequalities, but also by the racialised nature of global (and local) AIDS discourse, with its roots in European colonialism. Paradoxically, AIDS carries associations both with whites and with Africans. Racism and xenophobia were apparent in explanations of the presumed origins of the epidemic, where images were invoked of sex between humans and animals, or eating the raw flesh of green monkeys (Aggleton and Parker 2002). This racism has both imbued dominant images of the epidemic, and been reproduced through them (Aggleton and Parker 2002). Sub-Saharan Africa is the global region with by far the most severe experience of AIDS. Biomedical discourse has cast the blame for AIDS on individual risk behaviour which in Africa has been attributed to cultural difference (Schoepf 2001). Given the sexually transmitted nature of the disease, inferences are drawn by some about African sexual practices (although there is no demonstrable link between HIV prevalence and cultural differences in sexual behaviour (UNAIDS 2002)). Africans are thereby portrayed as the causes of their own misfortunes (Aggleton and Parker 2002).

At the same time, AIDS is often associated by African people with outsiders - it is said to come from 'elsewhere'. There is a perception among many in Nigeria that AIDS is a disease of foreigners (Alubo et al 2002). Sometimes, particularly in southern Africa, AIDS is associated specifically with whites. Both the 'indigenous' white population and visitors are blamed for introducing a white 'gay plague' into Africa's heterosexual population. In Lesotho, the first reported case of AIDS was a white man, a fact that dominated people's perceptions of the disease for some years. 'In the eyes of some African and Asian leaders, HIVIAIDS has been viewed as a disease of the West, linked to the weakness of family structures, liberal social values and moral decline' (Aggleton and Parker 2002, p. 9). 
These harmful racialised discourses have roots in and perpetuate colonial relationships between Africa and the West. They are present in the research encounter, but unlike economic injustices remain unspoken. They are felt as discomfort: as white women, we feel conscious of our bodies and uncomfortable in our skins. Emotions are aroused in researchers and researched, but all are reluctant to speak in such a way as to bring these to the foreground. These discourses, then, contribute to the difficulty of an open dialogue about AIDS.

\section{Stigma}

Research with AIDS-affected people must also take into account the stigma that informs emotional impacts of, and reactions to, the disease. As early as 1987, Jonathan Mann, then director of the WHO Global Programme on AIDS, described three phases of the epidemic: the epidemic of HIV, the epidemic of AIDS, and the epidemic of stigma, discrimination and denial. In his assessment, the latter was 'as central to the global AIDS challenge as the disease itself' (Mann 1987, cited in Parker and Aggleton 2002). While AIDS is almost universally stigmatised, this plays out locally in different ways.

Stigma exists in relation to moral codes. As 'a construction of deviation from some ideal or expectation' (Alonzo and Reynolds 1995, cited in Taylor 2001), stigma is an instrument of social control, expressed through disidentification, with stigma commonly experienced by individuals as shame (rather than guilt, which is a form of self-control (Solomon 1996)). The attachment of stigma to disease is not uncommon, particularly where the disease is severe, disfiguring, incurable and progressive (ICRW 2002a). Such conditions evoke strong emotional responses such as fear and revulsion (Taylor 2001). The stigmatisation is more marked where disease transmission is perceived to be a result of individual behaviour, especially where this transgresses social norms (ICRW 2002a). Thus AIDS-related stigma interacts with pre-existing prejudices connected with sexuality, gender, race and poverty (Parker and Aggleton 2002). Fears about contagion and disease are thereby compounded by deep-rooted anxieties about social breakdown.

According to UNAIDS (2001, p. 1), 'stigma ... undermines prevention, care and support; it also increases the impact of the epidemic on individuals, families, communities and nations.' Stigmatisation 'silences and saps the strength of alreadyweakened individuals and communities, and causes people to blame themselves for their predicament' (Aggleton and Parker 2002, p. 9-10). Stigma has psychological 
consequences, including depression, lack of self-worth, despair (Aggleton and Parker 2002), and since the immune system of a PLWHA is physically affected by their emotions (Weiser 1999), stigma and shame can damage an individual's physical health. Moreover, secondary stigma may become attached to the families and friends of those infected (ICRW 2002b). In societies where cultural systems emphasise collectivism over individuality, HIVIAIDS may be perceived as bringing shame on the family and community (Parker and Aggleton 2002).

Stigma is harmful, both in itself, and because it leads to discrimination against those stigmatised (Aggleton and Parker 2002). It arouses emotions of not just shame among those with HIVIAIDS, but also fear. People in Tanzania, for instance, expressed more concern about rejection and stigma than about the technical facts of AIDS (Lie and Biswalo 1994). Unsurprisingly, given the potential consequences, many people avoid finding out about their HIV status. Most PLWHAs who know their HIV status deny or hide their condition (Alubo et al 2002), and even continue to practise unsafe sex for fear of arousing suspicion (Aggleton and Parker 2002), putting themselves and others at further risk.

There is a need for anyone conducting research with AIDS-affected people to be sensitive to the stigmatisation of the disease, and to avoid any possibility that those involved in the research as participants might suffer stigma as a consequence. Some research in the past has arguably contributed to the stigmatisation of AIDS, particularly where it has represented PLWHAs as vectors of transmission rather than as people (Baggaley and van Praag 2000), and associated the disease with 'risk groups', inevitably stigmatising group members (Goldin 1994), and emphasised individual behaviour change, thereby casting responsibility on those who lack the power and autonomy to control their lifestyles.

Stigma shapes both the production and expression of emotion in research. The effects of stigma on research encounters are most likely to be manifested in silence. If a person affected by AIDS fears stigma, they are unlikely to be comfortable discussing AIDS in a research encounter. If researchers are sensitive to such fears, speaking of AIDS may be very difficult. The researchers' own concerns (perhaps culturally determined) about causing respondents to feel shame may paralyse any possibility of discussion. 


\section{Immediate circumstances}

Not only global power relations and societal moralities impinge on the research encounter such as to provoke emotional responses, but researchers intrude into the local worlds of their respondents which may be charged with emotion. The situations that confront individual AIDS-affected people differ in their details, but are frequently harrowing.

Matseliso, for instance, was living in Maseru, caring for her own two children and two of her dead sister's children when she was interviewed. She also supported her older nieces and nephews who now lived alone, their parents having died. On the wall was a wedding photograph, in which she and her husband conformed to the Basotho ideal of plumpness. Her husband, a soldier, had died a year ago, and Matseliso was now very thin and clearly close to death. Yet in the course of the interview she constantly talked about getting better, perhaps because her child was present.

Talking with people about experiences associated with sickness and/or death among close relatives can provoke distress. A small number of the people we interviewed, both adults and children, were reduced to tears when talking about their own situations, especially about relatives who had died. Being in a situation where people we know little are in a highly emotional state, particularly where they are distressed, causes discomfort for the interviewer. Researchers are therefore likely to avoid or move discussion away from topics that arouse such emotions among interviewees.

\section{Managing emotions in research}

In situations where research encounters are likely to give rise to heightened emotional responses, it is appropriate to attempt to manage the research such that the emotions that are provoked harm neither the research participants nor the researchers nor the research itself. Assessing what is harmful is not easy, but below we outline three ways in which we sought to manage the way emotions intervened in the young AIDS migrants research outlined above. We then move on to consider how such strategies sit ambiguously in relation to guidelines for ethical research.

\section{Dealing with distress}

We did not desist from talking about sickness and death with children and adults, despite our awareness that such conversations may be distressing for some participants. On the very few occasions that a person clearly became upset, the interview was ended, unless, as usually happened, the interviewee expressed a wish 
to keep going. One girl in Lesotho whose mother had recently died became very upset and cried, but wanted to continue talking about her situation. It is perhaps significant to recognise that as researchers we may not be causing the distress, but merely provoking it into the open, and thereby exposing ourselves to it. While this is uncomfortable for the researcher, the interviewee is not necessarily 'harmed' by the experience. Distress associated with sickness and death is 'natural'; talking and releasing emotions, whether of sadness or anger, can be cathartic. This is not to suggest that it is appropriate to subject a person to serious and prolonged distress (see Robson 2001). We would argue, on the basis of ethics of care, that the way in which we respond to such a situation should be consistent with both our emotional responses to the situation and theirs.

Our ability to deal with situations in which people become distressed is, however, inhibited by the fact that, as researchers, we do not expect to deal with people's emotions. Because the role of emotions in research is ignored, no attention has been given to training researchers in dealing with such situations. As a consequence we cannot feel confident in dealing with people in distress without causing harm. Moreover, in the research reported here, we generally had only fleeting contact with the people whose lives we were researching, and were unable to communicate directly with people in their own languages. We were fortunate in that we were supported in some of the research by people who were trained in counseling. Our interpreter in Lesotho, who assisted with all interviews, was a counselor, and in Malawi the interviews with adult guardians and with street children were undertaken in the presence of trained counselors, working for local NGOs. Most other children were interviewed in school settings, with the support of their teachers close at hand.

\section{Permitting denial}

Although we were funded to conduct research specifically concerning young people's AIDS-related migration, the research agenda we presented to school children and adult community members focused on children's migration. Although we asked people about sickness and death in relation to their own families, and responded to emotional distress if and when it occurred, we did not ask anyone directly about AIDS. For the reasons outlined earlier, we felt that discussion of AIDS could arouse emotional responses that would be difficult for both the research participants and ourselves, and may hinder the progress of the research. 
In conjunction with our own silencing of our research agenda, we allowed participants to deny AIDS. If a family member had died, causing a child to move home, we enquired as to the cause of death. Many children, in particular, claimed they did not know what their parents had died of - they may not have known, or may have sought to hide a (suspected) truth. Many people, both adults and children, talked of symptoms rather than specifying diseases (see Table 1). No one named AIDS, though two people alluded to it as 'the youngsters' disease' or 'the common disease'. 'Something in the chest' and 'ulcers' are reportedly common euphemisms for AIDS in Lesotho. Many of the symptoms and diseases mentioned (most notably tuberculosis) could well be AIDS-related. Others (stitch, a slight headache) are clearly not normally fatal, and perhaps represent denial of AIDS. If a person told us their relative had died of a pain in the chest, or of stitch, we did not challenge them or enquire whether it might have been AIDS-related. When deaths were attributed to causes we suspected might be AIDS, we could not know whether our informants were aware (or suspicious) of the true cause of death, whether they wanted to keep it from us, or whether they simply could not speak of it.

Table 1: Explanations offered for deaths of adult relatives

\begin{tabular}{|c|c|c|c|c|c|c|c|}
\hline \multicolumn{2}{|l|}{ Lesotho } & & & \multicolumn{2}{|l|}{ Malawi } & \multirow{2}{*}{\multicolumn{2}{|c|}{$\begin{array}{l}\text { headache and } \\
\text { nose bleeds }\end{array}$}} \\
\hline TB & 20 & cancer & 1 & TB & 15 & & \\
\hline $\begin{array}{l}\text { something in } \\
\text { chest/chest pain }\end{array}$ & 6 & heart attack & 1 & malaria & 8 & slight headache & 1 \\
\hline car accident & 5 & bewitched & 1 & headache(s) & 6 & $\begin{array}{l}\text { slight } \\
\text { headache/minor } \\
\text { infection }\end{array}$ & 1 \\
\hline pneumonia & 3 & diabetes & 1 & sick & 6 & $\begin{array}{l}\text { headache/fever/i } \\
\text { nfection }\end{array}$ & 1 \\
\hline shot & 3 & deep cold & 1 & bewitched & 4 & $\begin{array}{l}\text { diarrhoea and } \\
\text { headaches }\end{array}$ & 1 \\
\hline stabbed & 2 & ulcers & 1 & diarrhoea & 3 & lump in neck & 1 \\
\hline 'murdered' & 2 & arthritis & 1 & 'a disease' & 3 & lump under arm & 1 \\
\hline stroke & 2 & lung disease & 1 & $\begin{array}{l}\text { problems with } \\
\text { legs }\end{array}$ & 2 & paralysis of legs & 1 \\
\hline stitch & 2 & $\begin{array}{l}\text { beaten to death } \\
\text { in conflict }\end{array}$ & 1 & $\begin{array}{l}\text { 'the common } \\
\text { disease' }\end{array}$ & 2 & $\begin{array}{l}\text { stomach/bowel } \\
\text { problems }\end{array}$ & 1 \\
\hline childbirth & 2 & $\begin{array}{l}\text { stress at } \\
\text { another's death }\end{array}$ & 1 & childbirth & 2 & stomach ache & 1 \\
\hline growth on brain & 1 & $\begin{array}{l}\text { 'things coming } \\
\text { out of vagina' }\end{array}$ & 1 & pains/swelling & 1 & $\begin{array}{l}\text { swellings in } \\
\text { stomach }\end{array}$ & 1 \\
\hline multiple disease & 1 & $\begin{array}{l}\text { 'youngsters' } \\
\text { disease' }\end{array}$ & 1 & $\begin{array}{l}\text { pains and } \\
\text { headache }\end{array}$ & 1 & typhoid & 1 \\
\hline \multirow[t]{4}{*}{$\begin{array}{l}\text { something } \\
\text { wrong with } \\
\text { bones }\end{array}$} & 1 & $\begin{array}{l}\text { lungs full of } \\
\text { water }\end{array}$ & 1 & swelling & 1 & cancer & 1 \\
\hline & & & & swollen leg & 1 & stroke & 1 \\
\hline & & & & shingles & 1 & fell down well & 1 \\
\hline & & & & cough & 1 & murdered & 1 \\
\hline
\end{tabular}




\begin{tabular}{|l|l|ll|ll|}
\hline & & malaria/heart & 1 & car accident 1 \\
\hline & headache $->$ & 1 & $\begin{array}{l}\text { heart } \\
\text { failure/blood } \\
\text { pressure }\end{array}$ & 1 \\
\hline
\end{tabular}

Source: focus groups with children; interviews with adult guardians

We did raise the subject of AIDS, but not in such a way as to imply that we suspected that those whose sickness or deaths we were discussing might have HIV. We asked children what they knew of AIDS, how it was contracted, and whether anyone in their communities or families was affected by it. All children denied knowing anyone affected, and most reported that those affected by AIDS were 'people with unbecoming behaviour' or 'dirty people', revealing the extent to which AIDS remains stigmatised. In interviews with adults, we asked about deaths in their communities and whether they knew the cause of these deaths, and also about whether the growing number of orphans resulted from AIDS. Although in Malawi, some people attributed deaths in their communities to AIDS, in Lesotho they did not.

By allowing participants to remain silent about AIDS within their families, we felt that we were protecting them from an interpersonal situation that could be emotionally taxing. We were doubtless protecting ourselves from discomfort, too. Furthermore, we were protecting the research: had we revealed at the outset that we were interesting in talking to people whose relatives had become sick or died of AIDS, it is extremely unlikely that anyone would have been willing to speak with us. The actual cause of death was not of great importance to the research as the consequences for children of sickness and death differ little irrespective of the cause.

\section{Tailoring dissemination}

We have disseminated our research findings in several ways in the countries where the research was conducted. Before leaving, we made posters for the participating schools. These reported the preliminary findings from the migration questionnaire results and did not mention AIDS. We also conducted workshops with NGO and government representatives. Here we related our research directly to AIDS. We subsequently produced two different versions of the final report. One report was distributed to schools and local communities. This was carefully edited and given the title 'Young Migrants in Southern Africa: moving in the wake of AIDS' so as not to imply that the children and families we had worked with were themselves affected by AIDS, as this could have stigmatised them within their communities. The relevance of the research in relation to the high incidence of AIDS was, however, discussed. By 
contrast, the 'official' report, entitled 'Young AIDS migrants', along with academic papers we have produced, explained that although we did not specifically ask about AIDS, we could legitimately infer that about two-thirds of the orphans in our study were in fact AIDS orphans.

Our caution concerning dissemination to research participants was motivated by a concern not to distress or stigmatise them: protecting ourselves or the research was not an issue in this regard. When addressing government and NGOs, however, we felt that it was important to make the link with AIDS. Although all orphans and vulnerable children may have similar experiences, the research is of greatest relevance to practitioners and policy makers when seen in relation to the rapidly increasing numbers of such children that is a direct outcome of the AIDS pandemic. Even in this context, however, the issue was emotive. In the first dissemination phase, some representatives of government and NGOs expressed strong feelings that we were wrong to relate our research to AIDS, a response that can best be interpreted in light of the global discourses that frame discussions between people from the West and from southern Africa on the subject of AIDS.

\section{A sense of right and wrong?}

To a large extent, in our research we did what we 'sensed' to be right. The term 'sense' (perhaps too vague to be useful?) suggests both an embodied feeling and the application of rationality. We tried to be sensitive to the emotions of others - to their 'sensibilities'. Talking about sickness and death, but not about AIDS, both seemed to us to be sensitive to those with whom we talked. The application of 'reason', and a universalist ethic, however, raises two ways in which our avoidance of talking about AIDS might be criticised.

\section{Breaching ethical codes}

It is clear that in conducting the research we failed to fully inform participants of what the research was 'about'. We concealed from them the fact that we would use what they told us to make inferences concerning the impacts of AIDS. As our focus was on the indirect impacts of AIDS - impacts which are similar for most orphans and vulnerable children, we could have undertaken a similar research project that did not have AIDS in its title. This would not, however, have resolved the question of how far we should make participants aware of the possible ways we (or others) might interpret what we learn in research encounters. 
Numerous authors have pointed to the inadequacies of ethical codes as universal prescriptions for research practice. Cloke (2002, p. 591) attributes any progress towards a more ethically sensitive geography, not to 'the imposition of new ethical codes or guidelines but more because of the introduction of more flexible prompts for moral contemplation which have stimulated and nurtured moral imaginations in human geography research'. Cree et al (2002, p. 54) suggest similarly, '[t]he codes of ethics and guidelines for good practice which have been developed can never be more than this, because there will always be ambiguities and complexities', while Hay and Foley $(1998,180)$ go further to argue that '[t]he routinisation of ethical decision making through rigid institutional codes and practices denies or curbs the possibility of responsible citizenship.'

Nonetheless, the sense of having contravened ethical guidelines makes us uncomfortable. Wiener (2001) makes a relevant point in relation to the difficulties experienced by analysts in reconciling moral principles (codes of ethics) with their internal personal ethical attitude where there are dilemmas concerning confidentiality. She suggests that most analysts try to find a compromise position: a 'mental and emotional ethical space' (p.431).

\section{Reinforcing stigma}

That stigma is damaging has already been stated. One of the most harmful impacts of the stigmatisation of AIDS is the silence it provokes. 'Fears of the consequences of open discourse and self-identification have created a silence that threatens all of us' (Goldin 1994, p.1359). The silencing of AIDS is not only harmful to those who are at risk due to lack of knowledge. It has also "caused those infected with HIV and affected by the disease to feel guilty and ashamed, unable to express their views and fearful that they will not be taken seriously' (Aggleton and Parker 2002, p. 5), and even causes people to deny themselves the possibility of treatment, care and community support (Baylies and Bujra 1997). The WHO has long recognised denial as one of the greatest obstacles to AIDS prevention (WHO Global Programme on AIDS 1991), and the silence of political leaders has been particularly damaging in this regard (Aggleton and Parker 2002).

The advantages to society in general of more open discussion of AIDS seem clear. Yet, despite the difficulties stigma presents for the prevention and treatment of AIDS, in our research we operated within the 'culture of silence' that surrounds the 
epidemic. In this respect our silence seems unethical - could we not have confronted stigma through the research process, by encouraging open dialogue?

Although openness is doubtless 'good for society', it does put the individual at risk. Goldin (1994) points to the tension between the rights of the directly affected individual and those of the rest of society. Research by the ICRW (2002b) in three African countries found that while most people expressed a belief that PLWHAs should disclose their status, in practice very few felt able to do so, because they feared stigma. Given an appropriate context, it might be possible to support people in open dialogue. Research among Aboriginal people in Canada suggests that giving PLWHAs an environment in which they feel a sense of support and an opportunity to express themselves without stigma or judgement encourages them to take better care of themselves (Weiser 1999). It has been argued that the concern of the Western human rights lobby over confidentiality adds a new layer of AIDS-related stigma in African societies (Allen and Heald 2004). Nonetheless, for the reasons outlined earlier, an encounter between Western researchers on relatively short visits and southern Africans is not an ideal context for breaking down stigma.

\section{An uncomfortable silence?}

Talking openly about AIDS with AIDS-affected people in southern Africa is difficult and may, in some circumstances, be impossible. This raises the question of the extent to which it is important for people specifically to name AIDS. ICRW (2002b, p. 3) researchers observed that in interviews people were unwilling to name AIDS openly, preferring to talk in abstract terms, or using such descriptors as 'that disease we learned about.' Elsewhere, people employ a witchcraft metaphor in discussions of AIDS. This may not conflict with scientific knowledge of the disease, as Ashforth (2001) points out in relation to South Africa. Farmer (1994), similarly, discusses the way in which Haitians conceive of AIDS as (among other things) sent through sorcery. People would see such explanations as in no way inconsistent with a knowledge that it was caused by a 'microbe'. Metaphors do not necessarily indicate ignorance, or even complete denial - just an unwillingness to talk openly. Appropriating the diagnosis of witchcraft may even be helpful insofar as it allows those affected to lay blame rather than accept blame, and thereby to avoid stigma (Baylies and Bujra 1997).

Research in 'contact zones' is uncomfortable: the rules that one side finds comforting may cause discomfort to the other. As Besio (2003, p. 27) remarks, '[m]any, if not 
most, researchers would rather not locate themselves or their research in a contact zone, given Pratt's description [cited above]. Coercion? Radical inequality? Intractable conflict? These words describe the antithesis of desirable feminist and most if not all research interactions'. It is not particularly helpful, however, to insist that those we research with must speak in our language, use our terms: that if we must speak openly, not in metaphor, then we cannot communicate at all.

To cease to conduct research where it is impossible to be explicitly open about the research without causing a degree of emotional distress to participants would inhibit research relating to many areas of human experience. If we are to continue to conduct research on such issues it is necessary to make judgements about how open to be about the way the research might be interpreted and how cautious to be about evoking negative emotions. In making such judgements, researchers should be governed by rationality and emotion, or, simply, '[t]o act ethically requires a person to listen to both head and heart' (Silk 2000, 306).

Lastly, there is a temporality to the relationship between emotions and research that is worth noting. Contexts change over time, and with them the emotions that are provoked. Malawi has a longer history of AIDS than Lesotho, and at the time of the research, participants discussed the disease more freely there. Although the initial research was limited to two and a half months in each country, we returned for a further phase of dissemination two years on. People in all four communities welcomed our research findings and were by this time much more willing to discuss AIDS in relation to its impacts on their own communities. This raises the question of whether we should have waited until we could undertake the research in an entirely transparent way. On our return to southern Africa, people in the local research communities as well as policy makers and practitioners had 'woken up' to the pandemic and were eager to learn what we had found. We were able to supply a knowledge gap that had arisen in our absence, and at this stage to discuss openly the impacts of AIDS. Had we not undertaken the research, this would have been impossible. Furthermore, it is possible that through our research, particularly by raising the subject of AIDS in a non-threatening way, we had not simply generated findings to fill a hunger that would arise spontaneously, but had contributed to a growing awareness of the pandemic and its existing and potential effects. Rather than reinforcing the silencing of the pandemic, our cautious approach may have gone a little way towards exposing it. 


\section{Conclusions}

Ethical research needs to take account of the emotions of both researchers and researched. This is not to suggest a simplistic avoidance of all 'negative' emotions on either side. We should not be diverted from what we 'sense' to be right because of our own fear or guilt or embarrassment. Neither should we assume that the expression of negative emotions on the part of those we research is necessarily harmful (any more than we should assume that arousing 'positive' emotions means that we are doing good). Our own emotions and the way they make us sensitive to the emotions of others are a valuable part of the way we relate with people affected by the frightening and distressing impacts of AIDS.

Our emotions do not present us with clear-cut answers. Sense of right and wrong is more than just a feeling, it needs to be rationally justifiable. It also confronts us with uncomfortable contradictions. Universalist ethics of justice, as expressed in ethical codes, might indicate that our research was ethically wrong. Two forms of harm may have been implicated: our failure to fully disclose our purpose arguably both deceived participants and, perhaps more seriously, contributed to the silencing and related stigmatisation of AIDS. However, from the viewpoint of an ethic of care, taking account of the emotional context of interpersonal relations, it might be argued that we undertook the research in such a way as to avoid certain types of harm: not only emotional distress, but also the direct stigmatisation of individuals and families. Beyond these varied forms of harm, we should also consider the harm of not having undertaken research which was ultimately of interest to participants and potentially beneficial, not only for the children involved in our own research, but also others similarly affected by HIVIAIDS. Whereas, as academic researchers, we are illequipped to break down stigma and denial at a local level with confidence that we are not doing harm, we are able to deliver our findings to, and work with representatives of governments and NGOs, who might be able to implement positive change locally.

The choices that faced us in undertaking the research were not simply questions of global justice versus immediate circumstance or ends versus means, but involved a more complex navigation of the intersections of global and local, justice and care. 'Without emotion, without caring, a theory of justice is just another numbers game ... Reason and emotion are not two conflicting and antagonistic aspects of the soul. Together they provide justice, which is neither dispassionate nor "merely emotional" (Solomon 1995 cited in Smith 1998, p. 34). Professional and substantive ethics are 
inevitably connected in geography - 'process and product, context and content, are not comprehensible outside of the other' (Proctor 1999, p. 6).

\section{References}

Aggleton P and Parker R 2002 A conceptual framework and basis for action: HIVIAIDS stigma and discrimination UNAIDS, Geneva

Alderson P 1995 Listening to children: children and social research ethics Barnardo's, London

Allen T and Heald S 2004 'HIVIAIDS policy in Africa: what has worked in Uganda and what has failed in Botswana?' Journal of International Development 16, 1141-1154

Alubo O, Zwandor A, Jolayemi T and Omudu E 2002 'Acceptance and stigmatization of PLWA in Nigeria' AIDS Care 14(1), 117-126

Ansell N and van Blerk L 2004 'Children's migration as a household/family strategy: coping with AIDS in Malawi and Lesotho' Journal of Southern African Studies 30(3), 673-690

Ashforth A 2001 AIDS, witchcraft and the problem of power in post-Apartheid South Africa School of Social Science, Institute for Advanced Study, Princeton NJ

Baggaley R and van Praag E 2000 'Antiretroviral interventions to reduce mother-tochild transmission of human immunodeficiency virus: challenges for health systems, communities and society' Bulletin of the World Health Organization 78(8), 1036-1044

Baylies C and Bujra J 1997 'Social science research on AIDS in Africa: questions of content, methodology and ethics' Review of African Political Economy 73, 380-387

Benner P 2000 'The roles of embodiment, emotion and lifeworld for rationality and agency in nursing practice' Nursing Philosophy 1, 5-19

Besio K 2003 'Steppin' in it: postcoloniality in northern Pakistan' Area 35(1), 24-33

British Sociological Association 2002 'Statement of ethical practice' , accessed 21/05/03, http://www.britsoc.org.uk/about/ethic.htm

Campbell C 1999 'Action as will-power' The Sociological Review, 48-61

Cloke P 2002 'Deliver us from evil? Prospects for living ethically and acting politically in human geography' Progress in Human Geography 26(5), 587-604

Corbridge S 1998 'Development ethics: distance, difference, plausibility' Ethics, Place and Environment 1(1), 35-53 
Cree V E, Kay H and Tisdall K 2002 'Research with children: sharing the dilemmas' Child and Family Social Work 7, 47-56

Cutchin M P 2002 'Ethics and geography: continuity and emerging syntheses' Progress in Human Geography 26(5), 656-664

Damasio A 1999 The feeling of what happens: body, emotion and the making of consciousness Heinemann, London

Farmer P 1994 'AIDS-talk and the constitution of cultural models' Social Science and Medicine 38(6), 801-809

Farmer P et al 2001 'Community-based approaches to HIV treatment in resourcepoor settings' The Lancet 358, 404-409

Gilligan C 1982 In a different voice: psychological theory and women's development Harvard University Press, London

Goldin C S 1994 'Stigmatization and AIDS: critical issues in public health' Social Science and Medicine 39(9), 1359-1366

Gormley N and Bondi L 1999 'Ethical issues in practical contexts' in Proctor J D and Smith $D$ M (eds) Geography and ethics: journeys in a moral terrain Routledge, London

Haraway D 1995 'Cyborgs and symbionts: living together in the new world order' in Gray C H (ed) The cyborg handbook Routledge, London

Hay I and Foley P 1998 'Ethics, geography and responsible citizenship' Journal of Geography in Higher Education 22(2), 169-183

ICRW 2002a Addressing HIV-related stigma and resulting discrimination in Africa: a three-country study in Ethiopia, Tanzania and Zambia International Center for Research on Women, Washington DC

ICRW 2002b Understanding HIV-related stigma and resulting discrimination in sub-Saharan Africa: emerging themes from early data collection in Ethiopia, Tanzania and Zambia International Center for Research on Women, Washington DC

Laurier E and Parr H 2000 'Emotions and interviewing in health and disability research' Ethics, Place and Environment 3(1), 98-102

Lie G and Biswalo P 1994 'Perceptions of the appropriate HIVIAIDS counsellor in Arusha and Kilimanjaro regions of Tanzania: implications for hospital counselling' AIDS Care 6(2), 139-151

Metzel D 2000 'Research with the mentally incompetent: the dilemma of informed consent' Ethics, Place and Environment 3(1), 87-90

Paley J 2002 'Virtues of autonomy: the Kantian ethics of care' Nursing Philosophy $3,133-143$ 
Parker R and Aggleton P 2002 HIVIAIDS-related stigma and discrimination: a conceptual framework and an agenda for action The Population Council/Horizons Program, Washington DC

Proctor J D 1999 'Introduction: overlapping terrains' in Proctor J D and Smith D M (eds) Geography and ethics: journeys in a moral terrain Routledge, London

Robinson F 1999 Globalizing care: ethics, feminist theory, and international relations Westview, Boulder $\mathrm{CO}$

Robson E 2001 'Interviews worth the tears? Exploring dilemmas of research with young carers in Zimbabwe' Ethics, Place and Environment 4(2), 135-142

Ruiz P O and Vallejos R M 1999 'The role of compassion in moral education' Journal of Moral Education 28(1), 5-17

Schoepf B G 2001 'International AIDS research in anthropology: taking a critical perspective on the crisis' Annual Review of Anthropology 30, 335-361

Silk J 1998 'Caring at a distance' Ethics, Place and Environment 1(2), 165-182

Silk J 2000 'Caring at a distance: (im)partiality, moral motivation and the ethics of representation' Ethics, Place and Environment 3(3), 303-309

Silverstein K 1999 Millions for Viagra, pennies for diseases of the poor, The Nation, Nairobi

Smith D M 1994 'On professional responsibility to distant others' Area 26(4), 359-367

Smith D M 1997 'Back to the good life: towards an enlarged conception of social justice' Environment and Planning D: Society and Space 15, 19-35

Smith D M 1998 'How far should we care? On the spatial scope of beneficence' Progress in Human Geography 22(1), 15-38

Smith D M 1999 'Conclusion: towards a context-sensitive ethics' in Proctor J D and Smith D M (eds) Geography and ethics: journeys in a moral terrain Routledge, London

Solomon R C 1996 'Emotions, ethics, and the 'internal ought" Cognition and Emotion 10(5), 529-550

Solomon R C 1997 'Beyond ontology: ideation, phenomenology and the cross cultural study of emotion' Journal for the Theory of Social Behaviour 27(2/3), 289-303

Taylor B 2001 'HIV, stigma and health: integration of theoretical concepts and the lived experiences of individuals' Journal of Advanced Nursing 35(5), 792798

UNAIDS 2000 Report on the global HIVIAIDS epidemic. UNAIDS, Geneva 
UNAIDS 2001 Advocacy for action on stigma and HIVIAIDS in Africa UNAIDS Intercountry Team for Eastern and Southern Africa, Pretoria

UNAIDS 2004 Report on the global HIVIAIDS epidemic. UNAIDS, Geneva

USAID/UNICEF/UNAIDS 2002 Children on the brink 2002: a joint report on orphan estimates and program strategies USAID/UNICEF/UNAIDS

Valentine G 2003 'Geography and ethics: in pursuit of social justice - ethics and emotions in geographies of health and disability research' Progress in Human Geography 27(3), 275-380

Weiser J 1999 'Adapting traditional healing practices' AIDS Action 46, 7

Wenstop F and Magnus P 2001 'Value focused rationality in AIDS policy' Health Policy 57(1), 57-72

Whatmore S 1997 'Dissecting the autonomous self: hybrid cartographies for a relational ethics' Environment and Planning D: Society and Space 15, 3753

WHO Global Programme on AIDS 1991 'AIDS: credible messengers' World AIDS Day Features 1, 1-3

Widdowfield R 2000 'The place of emotions in academic research.' Area 32(2), 199208

Wiener J 2001 'Confidentiality and paradox: the location of ethical space' Journal of Analytical Psychology 46(3), 431-442

Wilton R D 2000 "Sometimes it's OK to be a spy': ethics and politics in geographies of disability' Ethics, Place and Environment 3(1), 91-97

Young L and Ansell N 2003 'Fluid households, complex families: the impacts of children's migration as a response to HIVIAIDS in southern Africa' Professional Geographer 55(4), 464-479

\footnotetext{
Notes

${ }^{1}$ Indeed, moral universalism is arguably itself historically and culturally specific: Kant has been criticised as Eurocentric in his advocacy of the autonomous self (Paley 2002), and Habermas has identified how the universalist notion of 'basic rights' emerged in Europe over the past two to three centuries (Smith 1999).

${ }_{2}^{2}$ e.g. UK National Children's Bureau Guidelines for Research 1993, Centre of the Child and Society, University of Glasgow Code of Practice for Research Involving Children (cited in Cree et al 2002), Priscilla Alderson's (1995) Listening to Children.
} 